\title{
Research \\ Is thenar tissue hemoglobin oxygen saturation in septic shock related to macrohemodynamic variables and outcome?
}

\author{
Didier Payen ${ }^{1}$, Cecilia Luengo ${ }^{1,2}$, Laurent Heyer ${ }^{1}$, Matthieu Resche-Rigon ${ }^{3}$, Sébastien Kerever ${ }^{1}$, \\ Charles Damoisel ${ }^{1}$ and Marie Reine Losser ${ }^{4}$
}

\begin{abstract}
${ }^{1}$ Department of Anesthesiology \& Critical Care Medicine - SAMU and Laboratory of Anesthesiology, EA322, Hospital Lariboisière, AP-HP and Paris 7 Diderot University, 2 rue Ambroise Paré, 75010 Paris, France

${ }^{2}$ Intensive Care Unit, Critical Care Patient Unit, Department of Medicine, University of Chile Clinical Hospital, Av. Santos Dumont 999, Independencia 8380456, Santiago, Chile

${ }^{3}$ Department of Biostatistic and Medical Informatic, Saint Louis Hospital, AP-HP and Paris 7 University, 75010 Paris, France

${ }^{4}$ Department of Anesthesiology \& Critical Care Medicine, Saint Louis Hospital, AP-HP and Paris 7 Diderot University, 75010 Paris, France
\end{abstract}

Corresponding author: Didier Payen, dpayen1234@aol.com

Published: 30 November 2009

This article is online at http://ccforum.com/content/13/S5/S6

(c) 2009 BioMed Central Ltd
Critical Care 2009, 13(Suppl 5):S6 (doi:10.1186/cc8004)

Conclusions: The alteration of $\mathrm{StO}_{2}$ reperfusion slope in septic shock patients compared with healthy volunteers was related with macrohemodynamic, microhemodynamic and metabolic parameters. The addition of the worst value of the day $1 \mathrm{StO}_{2}$ reperfusion slope improved the outcome prediction of Simplified Acute Physiology Score II and SOFA scores. forearm skin blood flow velocity using laser Doppler (LD) determine the relationship of macroperfusion and microperfusion parameters, and to test the relationship of the worst NIRS parameters during the first 24 hours of shock with 28-day prognosis.

Methods: A prospective, observational study was performed in a 21-bed university hospital surgical intensive care unit. Forty-three septic shock patients with at least another organ failure underwent a 3-minute, upper arm (brachial artery) vascular occlusion test (VOT). Microperfusion parameters (thenar eminence $\mathrm{StO}_{2}$ and forearm LD skin blood flow) were collected on days 1, 2 and 3, before (baseline $\mathrm{StO}_{2}$ and LD values) and during the 3-minute VOT with calculation of occlusion and reperfusion slopes for $\mathrm{StO}_{2}$ and LD. Daily Sequential Organ Failure Assessment (SOFA) score, macrohemodynamic parameters (systolic arterial blood pressure, cardiac output (pulmonary artery catheter or transesophageal Doppler), mixed venous oxygen saturation (pulmonary artery or superior vena cava catheter)) and metabolic parameters $(\mathrm{pH}$, base excess, lactate) were determined.

Results: Baseline $\mathrm{StO}_{2}$ (82\% (75 to 88) vs. $89 \%$ (85 to 92), $P=0.04)$ and reperfusion slope $(2.79 \% /$ second (1.75 to 4.32$)$ vs. $9.35 \% /$ second (8.32 to 11.57 ), $P<0.0001$ ) were lower in septic shock patients than in healthy volunteers. $\mathrm{StO}_{2}$ reperfusion slope correlated with occlusion slope $(P<0.0001)$, cardiac output $(P=0.01)$ and LD reperfusion slope $(P=0.08)$, and negatively with lactate level $(P=0.04)$. The worst $\mathrm{StO}_{2}$ reperfusion slope during the first day of shock was lower in nonsurvivors than in survivors $(P=0.003)$ and improved significantly the predictive value of Simplified Acute Physiology Score II and SOFA scores.

\section{Introduction}

Septic shock is described as a distributive shock, requiring fluid and vasopressor administration [1]. In the recent past, evidence for microcirculatory failure as a motor of organ failure during septic shock has grown. It has been shown that distribution of flow within a tissue is impaired by oxygen shunting $[2,3]$, cell aggregation, thrombosis [4], vasoconstriction [5] and/or tissue edema [6]. In the early phase of septic shock, early goal-directed cardiovascular optimization seems more efficient than the conventional strategy [7]. Despite this strategy, some patients continue to have abnormal microperfusion [8], which has been proposed to be targeted therapeutically with a fluid challenge [8], nitric oxide donors $[9,10]$ or activated protein C [11,12]. Before integrating microperfusion parameters into clinical strategies, a better characterization and understanding of microperfusion abnormalities is needed.

Among the tools available for microperfusion assessment, near-infrared spectroscopy (NIRS) seems promising. It has been shown in different life-threatening conditions that tissue hemoglobin oxygen saturation $\left(\mathrm{StO}_{2}\right)$ characterizes tissue hypoperfusion and effectiveness of therapies in trauma

$\mathrm{LD}=$ laser Doppler; NIRS = near-infrared spectroscopy; $\mathrm{ScvO}_{2}=$ central venous oxygen saturation; SOFA = Sequential Organ Failure Assessment; $\mathrm{SpO}_{2}=$ pulse oxymetry; $\mathrm{StO}_{2}=$ tissue hemoglobin oxygen saturation; $\mathrm{SvO}_{2}=$ mixed venous oxygen saturation; TPU = tissue perfusion units; VOT $=$ vascular occlusion test. 
[13-17], septic shock [18-22], and other acute systemic inflammatory conditions [23]. The large overlap of $\mathrm{StO}_{2}$ values between healthy subjects and septic shock patients [15-18] largely limits the interest of this parameter for individual care. As a consequence, a method to better evaluate the tissue micro-oxygenation in septic shock is needed. In this respect, a vascular occlusion test (VOT) combined with $\mathrm{StO}_{2}$ measurement has been proposed [17-20].

Measuring $\mathrm{StO}_{2}$ with a VOT provides a functional test having several potential determinants. These determinants and their relative impact during septic shock remain to be clarified so they can be interpreted adequately before making decisions. The $\mathrm{StO}_{2}$ occlusion slope was shown to relate to tissue oxygen consumption $[18,19,24]$, and the $\mathrm{StO}_{2}$ reperfusion slope was proposed to evaluate tissue flow reperfusion and vascular recruitment $[18,22]$ and was found to be abnormal in septic shock [20-22]. The purpose of the present study was to quantify the micro-oxygenation parameters in a homogeneous septic shock population controlled for severity, to investigate the relationship of micro-oxygenation and macroperfusion parameters, to investigate the relationship of NIRS parameters and skin laser Doppler (LD) in the same conditions, and to evaluate the association between microoxygenation parameters and outcome.

\section{Materials and methods}

The present single-center study was prospectively conducted in the 21-bed surgical intensive care unit at the tertiary Lariboisière University Hospital, between January 2005 and August 2008. The study was approved by the Ethics Committee of the French Society of Intensive Care (CE-SRLF 07-185) and informed consent was given by patients' next of kin.

\section{Patients}

Forty-three patients suffering from septic shock and with at least one additional organ failure were consecutively enrolled. Septic shock was diagnosed according to the criteria given by the Consensus Conference [1]. Measurements were performed as early as possible within the first 24 hours after starting vasopressor therapy (norepinephrine $>0.05 \mu \mathrm{g} / \mathrm{kg} /$ minute). All septic shock patients were enrolled except those in which monitoring $\mathrm{StO}_{2}$ on the thenar eminence was not possible (one patient).

All patients were mechanically ventilated and invasively monitored for hemodynamic parameters with arterial and central venous catheters (Vigilance PreSep CEDV(X3820HS); Edwards Lifesciences, Irvine, CA, USA) or pulmonary artery catheters (Swan Ganz CCOmboV CCO/SvO2/CEDV; Edwards Lifesciences), with continuous measurement of central venous oxygen saturation $\left(\mathrm{ScvO}_{2}\right)$ or mixed venous oxygen saturation $\left(\mathrm{SvO}_{2}\right)$, respectively. Cardiac output was also measured, either by the thermodilution technique or by esophageal Doppler (CardioQ ED probe; Deltex, Brighton,
UK) [25]. Light sedation and analgesia were provided according to the evaluation of individual needs by the physician in charge (flunitrazepam 1 to $2 \mathrm{mg} /$ hour and fentanyl 50 to $200 \mu \mathrm{g} /$ hour, propofol $50 \mathrm{mg} /$ hour, or ketamine 50 to $200 \mathrm{mg} /$ hour). Measurements were performed distant from modifications in the sedation protocol (at least 6 hours) or in the cardiovascular support (at least 1 hour). Patients were treated according to written intensive care unit standard management for septic shock, very similar to the Surviving Sepsis Campaign [26]. Additional treatments such as recombinant human activated protein $\mathrm{C}$, hydrocortisone or nitric oxide donors were collegially decided. No interventions were based on measured $\mathrm{StO}_{2}$ parameters.

For each patient, the following data were collected. Routine laboratory items were measured on the first day of septic shock to calculate the Simplified Acute Physiology Score II [27] and the Sequential Organ Failure Assessment (SOFA) score [28]; repeated for calculation of the SOFA score on days 2 and 3 . Macrohemodynamic parameters measured were the heart rate, blood pressure, cardiac output, right atrial pressure, $\mathrm{ScvO}_{2}$ or $\mathrm{SvO}_{2}$ (catheter measurement) and peripheral oxygen saturation $\left(\mathrm{SpO}_{2}\right)$ (pulse oximetry Dräger SC 9000, adult disposable oximetry sensor Novadiem 3311V, Nellcor compatible; Drägerwerk AG \& Co. KGaA, Lübeck, Germany). The metabolic parameters of arterial and venous blood gases, arterial lactate, and hemoglobin concentration were also collected on days 1,2 and 3 and were compared with NIRS-derived parameters. Since $\mathrm{SvO}_{2}$ was measured either in the superior vena cava $\left(\mathrm{ScvO}_{2}\right)$ or in the pulmonary artery (mixed $\mathrm{SvO}_{2}$ ), we analyzed these data separately and then pooled the data after applying a correction for the $\mathrm{ScvO}_{2}$. Five percent was subtracted from the $\mathrm{ScvO}_{2}$ value, according to previous reports [29]. The day-to-day infusion rates of vasopressors, inotropes, and analgesic and sedative drugs during these 72 hours were also collected.

\section{Tissue hemoglobin oxygen saturation measurements}

$\mathrm{StO}_{2}$ was measured by a tissue spectrometer (InSpectra Model 325; Hutchinson Technology, Hutchinson, MN, USA), which uses reflectance-mode probes to measure scattering light reflected at some distance from where the light is transmitted into the tissue. The maximum depth of the tissue sampled is estimated to equal one-half of the distance between the probe's sending and receiving fibers (probe spacing) $[13,30]$, which was $25 \mathrm{~mm}$ in the present study. A light-scattering calibrator was used to normalize the tissue spectrometer during system startup and before each measurement. $\mathrm{StO}_{2}$ measurements were updated every 3.5 seconds [22]. This non-invasive technique measures the saturation ratio of oxygenated and deoxygenated hemoglobin. This ratio includes all vessels (arterioles, capillaries and venules) in the tissue sample volume illuminated by the NIRS sensor. The decision to measure $\mathrm{StO}_{2}$ at the skeletal muscle of the thenar eminence was based on several factors: this area (hand and thenar eminence) is an important target for 
vascular reflex adaptation [31], having an earlier and more amplified vascular response than many other tissues [32,33]; there is little signal influence of skin and fat tissue for a $12.5 \mathrm{~mm}$ depth of measurement [13,30]; and edema is more limited on this area [34]. The sensor was placed on the side free of an arterial catheter to avoid any potential interference.

$\mathrm{StO}_{2}$ monitoring continued for 72 hours after enrollment. In addition, a VOT was performed four times per day with a rigorous protocol: after a 5-minute baseline measurement, a sphygmomanometer cuff placed over the brachial artery was rapidly inflated to $300 \mathrm{mmHg}$ and maintained for 3 minutes to achieve stagnant arterial ischemia. The cuff was then abruptly deflated and measurements continued for 5 minutes.

The following parameters were measured or calculated from continuous numerical data stored in the device: after occlusion, the slope for $\mathrm{StO}_{2}$ decay was calculated from six to nine values and called the occlusion slope; similarly, after abrupt release of the cuff inflation, the reperfusion slope was computed on the basis of three or four $\mathrm{StO}_{2}$ ascending values. The slopes were calculated using statistical linear adjustment. When the linear correlation coefficient $R^{2}$ was $>0.90$, the slope was considered linear and expressed as a percentage per second (normal values \pm standard deviation: occlusion slope, $-0.46 \pm 0.17 \%$ /second; reperfusion slope, $9.82 \pm 2.11 \%$ /second). This strategy for measurements was repeated on days 1,2 and 3 . At day 1, the worst values for $\mathrm{StO}_{2}$ and VOT calculated parameters were used in survivors, nonsurvivors, and healthy subjects $(n=15)$ for comparison and for testing the outcome predictable value. Baseline $\mathrm{StO}_{2}$ and VOT parameters for healthy volunteers were collected in a semirecumbent position after 10 minutes of rest. Data from days 1,2 , and 3 were pooled for a correlation study between NIRS parameters, macrohemodynamic data, metabolic data and LD data. In addition, baseline $\mathrm{StO}_{2}$ values were compared with other oxygen saturations and the gradients between $\mathrm{StO}_{2}$ and $\mathrm{SvO}_{2}$ and between $\mathrm{SpO}_{2}$ and $\mathrm{StO}_{2}$ were computed.

\section{Laser Doppler}

The skin blood flow velocity was measured upstream of the $\mathrm{StO}_{2}$ probe, on the inner side of the homolateral wrist, using the LD technique. The probe was secured and connected to a dual-channel flowmeter (BLF21D; Transonic Systems, Ithaca, NY, USA). Cutaneous blood flow velocity $(1.2 \mathrm{~mm}$ deep, in arbitrary tissue perfusion units (TPU)) was continuously measured and recorded as a numerical signal onto a computer with an analog/digital transducer (Biopac Systems MP100; BIOPAC Systems, Inc, Goleta, CA, USA) and with data processing software (Acqknowledge 3.81; BIOPAC Systems, Inc).

The same occlusion test used for $\mathrm{StO}_{2}$ was applied for LD measurements (Figure 1). After baseline data registration, the stop flow (VOT) and the post-ischemic reperfusion flow
Figure 1

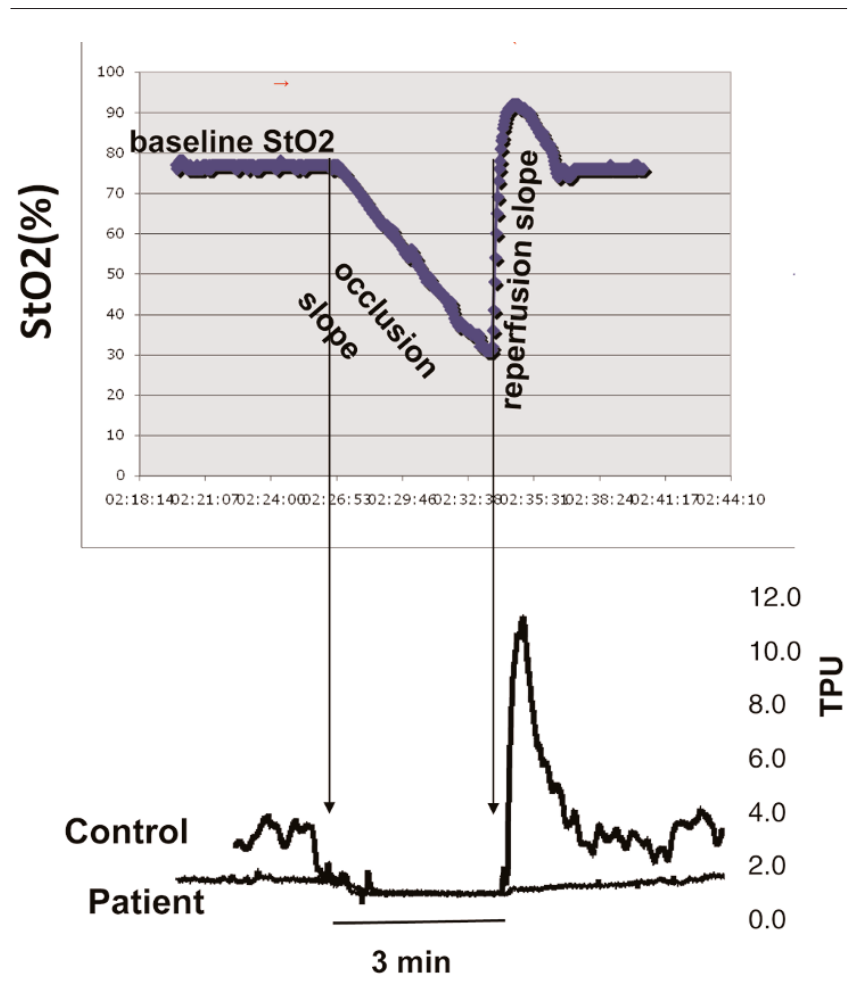

Time(min)

Tissue hemoglobin oxygen saturation and laser Doppler measurement. Example of a real tracing for tissue hemoglobin oxygen saturation $\left(\mathrm{StO}_{2}\right)$ and laser Doppler measurements obtained before and during the occlusion test. TPU, tissue perfusion units.

were registered. As shown in Figure 1, the LD flow signal shows a reperfusion peak flow before coming back to baseline. In addition to baseline values, the slope of reperfusion was calculated as described for $\mathrm{StO}_{2}$ using linear adjustment (normal value \pm standard deviation: baseline, 30.49 $\pm 21.30 \mathrm{TPU} /$ seconds (local data) [35]; reperfusion slope, $48.62 \pm 32.08 \mathrm{TPU} / \mathrm{seconds}$ ). The relative reperfusion hyperemia was also calculated from baseline to peak (absolute TPU value). Data from reperfusion were expressed as absolute changes, as well as the percentage of variation from the preocclusion value.

\section{Statistical analysis}

Data are summarized as the incidence and percentage for categorical variables. Quantitative variables are summarized as the median (25th to 75th percentiles). The reperfusion slope was dichotomized using the median value, which allowed fixing the threshold difference. The relationship between variables at day 1 (scores, macrohemodynamic, metabolic, NIRS and LD) and death within 28 days were tested by Wilcoxon test or Fisher exact test. Multivariate models were performed using multiple logistic regression. In 
model checking, we examined potential interactions and colinearity. Goodness of fit was evaluated using the method proposed by Le Cessie and Van Houwelingen. Models were compared using the log-likelihood ratio test. We used a linear mixed-effects model to analyze the pooled data from days 1 , 2 and 3 , and the relationships between $\mathrm{StO}_{2}$ and $\mathrm{SvO}_{2}$, between the reperfusion slopes of $\mathrm{StO}_{2}$ and $\mathrm{LD}$, between $\mathrm{StO}_{2}$ occlusion and reperfusion slopes, and between the $\mathrm{StO}_{2}$ reperfusion slope and macrohemodynamic or metabolic data. The predictive value on outcome for the $\mathrm{StO}_{2}$ reperfusion slope and SOFA score was calculated using a receiver operator characteristic curve with data obtained on day 1.

All tests were two-sided, at the 0.05 significance level. Analyses were carried out using the $\mathrm{R}$ statistical package [36].

\section{Results}

\section{Clinical characteristics}

Forty-three patients with septic shock were included in the study. Clinical characteristics are summarized in Table 1. By definition, all patients had cardiovascular dysfunction and at least one other organ dysfunction at the time of recruitment. According to collegial decision, 11 patients (25.6\%) received recombinant human activated protein $\mathrm{C}$ at the recommended dose rate and duration, 15 patients $(34.8 \%)$ received lowdose hydrocortisone (50 mg four times daily) with no fludrocortisone, and three patients (7\%) were treated with nitric oxide donors (molsidomine, 2 to $4 \mathrm{mg}$; Sanofi Aventis, Paris, France) [10]. The age of the 15 healthy volunteers ranged from 25 to 72 years.

The actual mortality rate was $34.9 \%$ (15 patients), consistent with a group at high risk of death. Of these 15 nonsurviving patients, two (13.3\%) received recombinant human activated protein $\mathrm{C}$ and four (26.6\%) received hydrocortisone. There were no differences in age, sex, primary sites of infection or Simplified Acute Physiology Score II scores between survivors and nonsurvivors. The SOFA score on day 1, however, was higher in nonsurvivors compared with survivors (median 13 (12 to 16$)$ vs. 9 (8 to 11$), P=0.001$ ).

Among the hemodynamic parameters (Table 2), only cardiac output was significantly different between survivors and nonsurvivors (6.8 (5.0 to 8.3) vs. 4.9 (4.1 to 6.9 ), $P=0.04$ ). The lactate level was higher in nonsurvivors compared with survivors (median 6.8 (5.3 to 8.8 ) vs. 3.1 (2 to 4 ), $P=0.001$ ), while the $\mathrm{pH}$ and base excess were lower in the former group of patients than in those who survived (7.2 (7.1 to 7.2) vs. 7.3 (7.2 to 7.4$), P<0.001$, and $-12.3(-14.25$ to -10.4$)$ vs. -7.3 ( -10 to -3.8$), P=0.004$, respectively) (Table 2 ). The hemoglobin concentration showed no difference between both groups $(P=0.51)$ and was considered adequate.

The evolution of patients surviving at least the first 3 days is described in Table 3 for the SOFA score, cardiovascular
Table 1

\begin{tabular}{|c|c|}
\hline Characteristic & Value \\
\hline Age (years) & 70 (56 to 81$)$ \\
\hline Sex (men) & $25(58.2)$ \\
\hline \multicolumn{2}{|l|}{ Sepsis origin } \\
\hline Abdominal & $22(51.2)$ \\
\hline Respiratory tract & $11(25.6)$ \\
\hline Skin/soft tissue & $4(9.3)$ \\
\hline Urinary tract & $2(4.7)$ \\
\hline Others & $4(9.3)$ \\
\hline $\begin{array}{l}\text { Patients with recombinant human activated } \\
\text { protein } \mathrm{C}\end{array}$ & $11(25.6)$ \\
\hline Patients with corticoids & $15(34.8)$ \\
\hline Patients with nitric oxide donors & $3(7)$ \\
\hline Simplified Acute Physiology Score II & 57 (46 to 70$)$ \\
\hline \multicolumn{2}{|l|}{ Sequential Organ Failure Assessment score: } \\
\hline Day 1 & $10(8$ to 13$)$ \\
\hline Day 2 & 12 (9 to 14$)$ \\
\hline Day 3 & $11(7$ to 14$)$ \\
\hline Outcome (alive/dead) & $28 / 15(65 / 35)$ \\
\hline
\end{tabular}

Data are presented as median (25th to 75 th percentiles) or $n(\%)$.

support, hemodynamic and metabolic items, $\mathrm{StO}_{2}$ and LD data. One can note the rapid evolution of the hemodynamic parameters, norepinephrine dose, metabolic status and $\mathrm{StO}_{2}$ parameters despite a relatively stable day-to-day SOFA score.

\section{Tissue hemoglobin oxygen saturation data}

The baseline $\mathrm{StO}_{2}$ was moderately lower in septic shock patients compared with healthy volunteers (82\% (75 to 88) vs. $89 \%$ ( 85 to 92 ), $P=0.04$ ). In addition, the reperfusion slope was lower in septic shock patients compared with volunteers (median 2.79\%/second (1.75 to 4.32) vs. 9.35\%/second (8.32 to 11.57), $P<0.0001$ ) (Figure 2a,b), with no difference for occlusion slopes $(P=0.11)$.

Looking at the survivors versus the nonsurvivors, the two groups had similar baseline $\mathrm{StO}_{2}$ values ( $82 \%$ (75 to 87 ) vs. $82 \% \quad(73$ to 92$), P=0.86)$ and occlusion slopes $(-0.35 \% /$ second $(-0.54$ to -0.24$)$ vs. $-0.3 \% /$ second $(-0.37$ to -0.25$), P=0.36$ ) (Table 3 ). The reperfusion slopes were significantly lower in nonsurvivors compared with survivors (median $1.88 \% /$ second (1.56 to 2.76 ) vs. $3.98 \% /$ second (2.25 to 6.04), $P=0.003$ ) on day 1 (Table 3 ). The difference for the reperfusion slope between the survivors and nonsurvivors related to intensive care unit death (odds ratio $=$ $0.46,95 \%$ confidence interval $=0.26$ to 0.83 ). 
Table 2

\begin{tabular}{|c|c|c|c|c|}
\hline Parameter & Total group $(n=43)$ & Survivors $(n=28)$ & Nonsurvivors $(n=15)$ & $P$-value \\
\hline Heart rate (beats/minute) & $108(90$ to 121$)$ & $108(90$ to 113$)$ & $110(89$ to 125$)$ & NS \\
\hline Systolic arterial pressure $(\mathrm{mmHg})$ & $115(100$ to 121$)$ & 115 (103 to 120$)$ & 114 (88.5 to 127$)$ & NS \\
\hline Diastolic arterial pressure $(\mathrm{mmHg})$ & 55 (47 to 62 ) & 56 (49 to 62 ) & 50 (45 to 62$)$ & NS \\
\hline Cardiac output (I/minute) & 5.9 (4.8 to 7.8$)$ & 6.8 (5.0 to 8.3$)$ & 4.9 (4.1 to 6.9$)$ & 0.04 \\
\hline Right atrial pressure $(\mathrm{mmHg})$ & 11 (8 to 13$)$ & 11 (8 to 13$)$ & 12 (9 to 15$)$ & NS \\
\hline $\mathrm{pH}$ & 7.3 (7.2 to 7.3$)$ & $7.3(7.2$ to 7.4$)$ & $7.2(7.1$ to 7.2$)$ & 0.0003 \\
\hline Base excess (mEq/l) & $-9.6(-11.35$ to -5.35$)$ & $-7.3(-10$ to -3.8$)$ & $-12.3(-14.35$ to -10.4$)$ & 0.004 \\
\hline Lactate (mmol/l) & 4.1 (2.2 to 5.5$)$ & $3.1(2.0$ to 4.0$)$ & 6.8 (5.3 to 8.8$)$ & 0.001 \\
\hline Hemoglobin (g/dl) & 9.9 (9.0 to 11.2$)$ & $10(9.2$ to 11.1$)$ & 9.7 (8.6 to 11.2$)$ & NS \\
\hline SAPS II & 57 (46 to 70$)$ & 56 (43 to 61$)$ & 65 (52 to 79$)$ & 0.08 \\
\hline SOFA score & $10(8$ to 13$)$ & $9(8$ to 11$)$ & $13(12$ to 16$)$ & 0.001 \\
\hline
\end{tabular}

Data are presented for patients with septic shock (total group), for survivors and for nonsurvivors as median (25th to 75th percentiles). NS, not significant; SAPS II, Simplified Acute Physiology Score II; SOFA, Sequential Organ Failure Assessment.

Table 3

\begin{tabular}{|c|c|c|c|c|c|c|}
\hline Parameter & $n$ & Day 1 & $n$ & Day 2 & $n$ & Day 3 \\
\hline SOFA score & 43 & 10 (8 to 13$)$ & 39 & $12(9$ to 14$)$ & 35 & $11(7$ to 14$)$ \\
\hline Norepinephrine ( $\mu \mathrm{g} / \mathrm{kg} / \mathrm{minute})$ & 43 & 0.59 (0.32 to 0.85$)$ & 35 & 0.47 (0.25 to 0.80$)$ & 24 & 0.30 (0 to 0.56$)$ \\
\hline Epinephrine ( $\mu \mathrm{g} / \mathrm{kg} / \mathrm{minute})$ & 5 & 0.26 (0.22 to 0.37$)$ & 4 & 0.45 (0.17 to 0.78$)$ & 2 & 0.71 (0.62 to 0.80$)$ \\
\hline Dobutamine ( $\mu \mathrm{g} / \mathrm{kg} /$ minute) & 4 & $10(7$ to 11$)$ & 4 & $6(2$ to 10$)$ & 2 & $6.3(5.7$ to 7.0$)$ \\
\hline Heart rate (beats/minute) & 43 & $108(90$ to 121$)$ & 35 & $101(80$ to 108$)$ & 25 & $80(74$ to 102$)$ \\
\hline Systolic arterial pressure $(\mathrm{mmHg})$ & 43 & $115(100$ to 121$)$ & 35 & $120(111$ to 130$)$ & 25 & 131 (109 to 147$)$ \\
\hline Diastolic pressure $(\mathrm{mmHg})$ & 43 & 55 (47 to 62$)$ & 35 & $58(52$ to 64$)$ & 25 & 61 (52 to 68$)$ \\
\hline Cardiac output (I/minute) & 33 & $5.9(4.8$ to 7.8$)$ & 28 & 6.3 (5.0 to 7.2$)$ & 16 & 5.3 (4.9 to 7.5$)$ \\
\hline Right atrial pressure $(\mathrm{mmHg})$ & 35 & 11 (8 to 13$)$ & 34 & $10(7$ to 14$)$ & 20 & $10(6$ to 11$)$ \\
\hline $\mathrm{pH}$ & 24 & 7.27 (7.22 to 7.33$)$ & 19 & 7.32 (7.28 to 7.39$)$ & 11 & 7.38 (7.35 to 7.41$)$ \\
\hline Base excess (mEq/l) & 20 & $-9.6(-11.4$ to -5.4$)$ & 18 & $-4.8(-8.0$ to -2.4$)$ & 11 & $-3.2(-6.0$ to 0.8$)$ \\
\hline Lactate $(\mathrm{mmol} / \mathrm{l})$ & 23 & $4.14(2.22$ to 5.51$)$ & 19 & 2.30 (1.56 to 5.62$)$ & 7 & 3.00 (1.98 to 3.88$)$ \\
\hline $\mathrm{SvO}_{2}(\%)$ & 39 & 75 (68 to 83$)$ & 34 & $74(66$ to 78$)$ & 22 & 70 (65 to 75$)$ \\
\hline Hemoglobin (g/dl) & 43 & 9.9 (9.0 to 11.2$)$ & 38 & $9.5(8.8$ to 11.0$)$ & 33 & $9.6(8.4$ to 10.0$)$ \\
\hline $\mathrm{SpO}_{2}(\%)$ & 43 & 99 (98 to 100$)$ & 38 & 99 (97 to 100$)$ & 33 & 99 (98 to 100$)$ \\
\hline $\mathrm{StO}_{2}(\%)$ & 43 & 82 (75 to 88$)$ & 36 & 85 (78 to 92$)$ & 25 & $88(80$ to 92$)$ \\
\hline $\mathrm{StO}_{2}$ occlusion slope (\%/second) & 43 & $-0.31(-0.47$ to -0.24$)$ & 34 & $-0.48(-0.65$ to -0.31$)$ & 21 & $-0.42(-0.62$ to -0.34$)$ \\
\hline $\mathrm{StO}_{2}$ reperfusion slope (\%/second) & 43 & 2.79 (1.75 to 4.32$)$ & 34 & 4.37 (2.98 to 6.72$)$ & 21 & 5.15 (3.67 to 6.85$)$ \\
\hline LD baseline flow (TPU) & 15 & $2.74(1.92$ to 5.65$)$ & 13 & 5.30 (1.88 to 7.56$)$ & 9 & 6.57 (3.87 to 11.92$)$ \\
\hline LD reperfusion slope (TPU/second) & 15 & $1.16(0.49$ to 2.64$)$ & 13 & 1.98 (1.58 to 4.36$)$ & 9 & $3.38(2.42$ to 4.31$)$ \\
\hline
\end{tabular}

Evolution at days 1, 2 and 3 of the Sequential Organ Failure Assessment (SOFA) score, the dose of vasopressor and inotropic drugs, and systemic (hemodynamic and metabolic) and microperfusion (near-infrared spectroscopy and laser Doppler (LD)) parameters in septic shock patients. Data are expressed as the median (25th to 75 th percentiles). $\mathrm{SvO}_{2}$, central venous oxygen saturation (central venous + added $5 \%$ of saturation or arterial pulmonary blood gases); $\mathrm{SpO}_{2}$, pulse oxymetry; $\mathrm{StO}_{2}$, tissue hemoglobin oxygen saturation; $\mathrm{TPU}$, tissue perfusion units. 
(a)

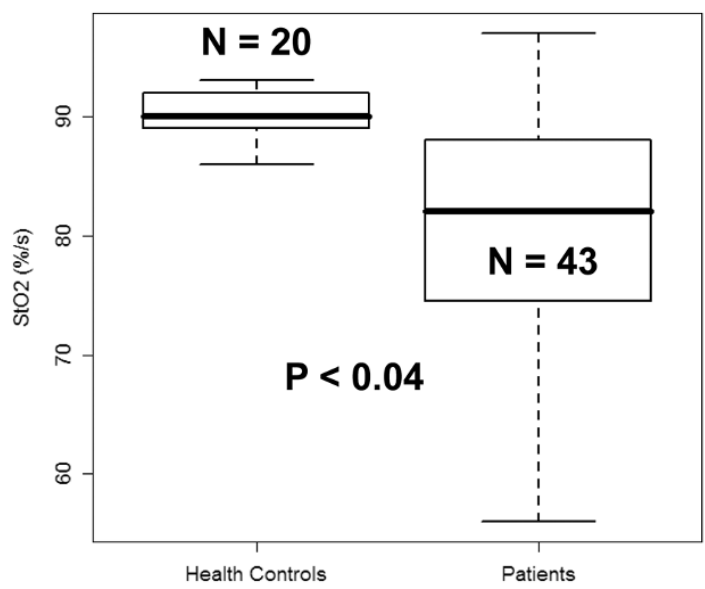

(b)

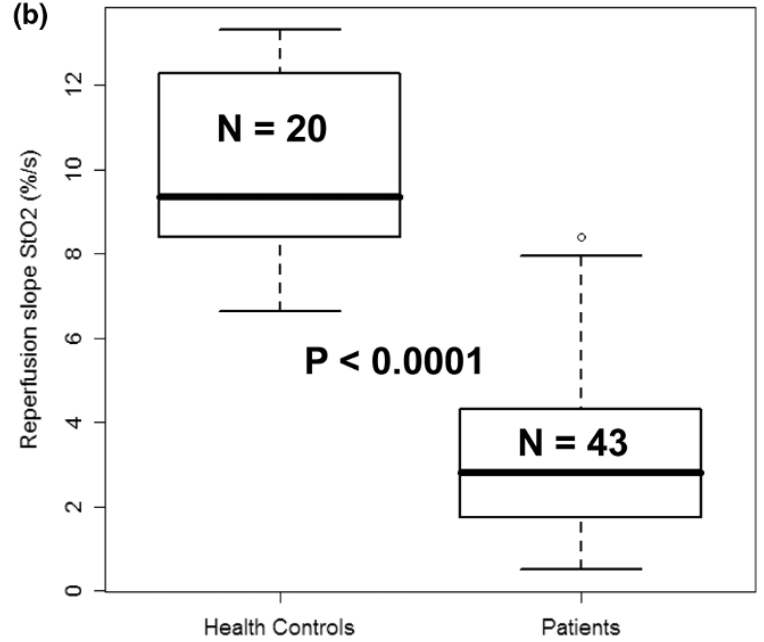

Baseline tissue hemoglobin oxygen saturation and the reperfusion slope. (a) Box plot for baseline tissue hemoglobin oxygen saturation $\left(\mathrm{StO}_{2}\right)$ in healthy volunteers compared with that for septic shock patients on day 1. (b) Box plot for reperfusion slope in healthy subjects compared with that for septic shock patients on day 1.

Table 4

Tissue hemoglobin oxygen saturation parameters measured at day 1

\begin{tabular}{|c|c|c|c|c|}
\hline Parameter & Total group $(n=43)$ & Survivors $(n=28)$ & Nonsurvivors $(n=15)$ & $P$-value \\
\hline $\mathrm{SpO}_{2}(\%)$ & 99 (98 to 100$)$ & 99 (97 to 100$)$ & 100 (99 to 100$)$ & 0.18 \\
\hline $\mathrm{StO}_{2}(\%)$ & 82 (75 to 88 ) & 82 (75 to 87$)$ & 82 (73 to 92$)$ & 0.86 \\
\hline $\mathrm{SvO}_{2}(\%)$ & 75 (68 to 83 ) & 76 (70 to 84$)$ & 73 (68 to 77$)$ & 0.22 \\
\hline$\Delta \mathrm{SpO}_{2}-\mathrm{StO}_{2}(\%)$ & 17 (9 to 24$)$ & 16 (9 to 22$)$ & 18 (7.5 to 25$)$ & 0.96 \\
\hline$\Delta \mathrm{StO}_{2}-\mathrm{SvO}_{2}(\%)$ & $5(-7$ to 19$)$ & $4.5(-3$ to 18.1$)$ & $10(-10.3$ to 20.5$)$ & 0.61 \\
\hline$\Delta \mathrm{StO}_{2}-\mathrm{SvO}_{2} / \mathrm{StO}_{2}$ & $0.06(-0.1$ to 0.2$)$ & $0.05(-0.04$ to 0.2$)$ & $0.14(-0.1$ to 0.2$)$ & 0.69 \\
\hline$\Delta \mathrm{StO}_{2}-\mathrm{SvO}_{2} / \mathrm{SvO}_{2}$ & $0.08(-0.03$ to 0.3$)$ & $0.05(-0.03$ to 0.3$)$ & 0.18 (0 to 0.3$)$ & 0.50 \\
\hline Occlusion slope (\%/second) & $-0.31(-0.47$ to -0.24$)$ & $-0.35(-0.54$ to -0.24$)$ & $-0.3(-0.37$ to -0.25$)$ & 0.36 \\
\hline Reperfusion slope (\%/second) & 2.79 (1.75 to 4.32$)$ & 3.98 (2.25 to 6.04$)$ & $1.88(1.56$ to 2.76$)$ & 0.003 \\
\hline
\end{tabular}

Tissue hemoglobin oxygen saturation $\left(\mathrm{StO}_{2}\right)$ parameters measured on day 1 in patients with septic shock (total group), in survivors and in nonsurvivors. Data are presented as median (25th to 75th percentiles). $\mathrm{SpO}_{2}$, pulse oxymetry; $\mathrm{SvO}_{2}$, central venous oxygen saturation (included mixed venous oxygen saturation and superior vena cava oxygen saturation $+5 \%$ ); $\Delta$, gradient between stated parameters.

No difference was observed in the gradients between $\mathrm{SpO}_{2}$ and $\mathrm{StO}_{2}$ or between $\mathrm{StO}_{2}$ and $\mathrm{SvO}_{2}$ in survivors and nonsurvivors (Table 3 and Table 4). There was also no correlation between $\mathrm{SpO}_{2}$ and $\mathrm{StO}_{2}$ (data not shown), nor between $\mathrm{StO}_{2}$ and $\mathrm{SvO}_{2}(P=0.86)$ (Figure 3).

Figure 4 shows the significant correlations observed with the reperfusion slope, which might clarify the determinants of such a parameter in septic shock. Among the hemodynamic and metabolic parameters evaluated on days 1, 2, and 3, we observed a positive correlation between the $\mathrm{StO}_{2}$ reperfusion slope and cardiac output $(P=0.01)$ and a negative correlation between the $\mathrm{StO}_{2}$ reperfusion slope and arterial lactate
$(P=0.04)$. The occlusion and the reperfusion slopes correlated well: the faster the $\mathrm{StO}_{2}$ decay during the stagnant ischemia, the faster the reperfusion slope $(P<0.0001)$. No correlation between the reperfusion slope and blood pressure, $\mathrm{pH}$ or base excess was observed.

The predictive value on outcome of the reperfusion slope was calculated using a receiver operator characteristic curve. The receiver operator characteristic curve showed the $\mathrm{StO}_{2}$ reperfusion slope as a good outcome predictor (area under the curve $=0.77$ ). The best cut-off value was $2.83 \% /$ second, with a sensitivity of $80 \%$ and a specificity of $67 \%$. In addition, using a multivariable model, the $\mathrm{StO}_{2}$ reperfusion slope 
Figure 3

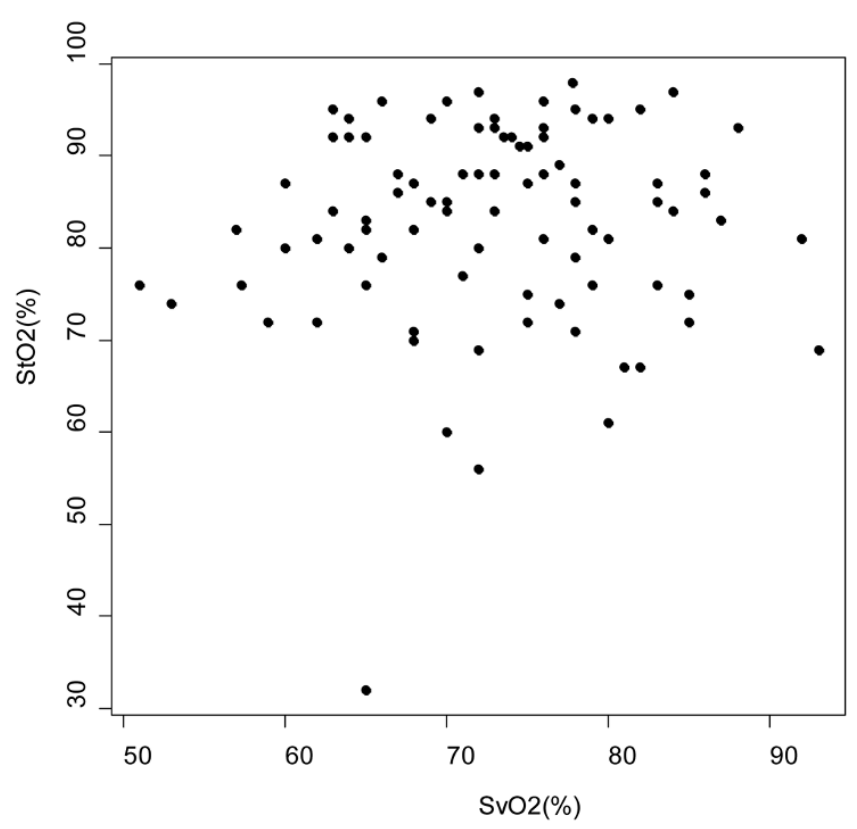

Correlation between central venous oxygen saturation and tissue hemoglobin oxygen saturation. Correlation between central venous oxygen saturation $\left(\mathrm{SvO}_{2}\right)$ and tissue hemoglobin oxygen saturation $\left(\mathrm{StO}_{2}\right)$ obtained during the first day of septic shock.

added a significant prognostic value both to the SOFA score $(P=0.037)$ (Figure 5$)$ and to the Simplified Acute Physiology Score II $(P=0.015)$ (data not shown).

\section{Laser Doppler data}

Fifteen (34.8\%) out of the 43 septic shock patients were also evaluated with the skin LD technique. Values obtained for the total group were: baseline, 2.74 TPU (1.92 to 5.65) (normal values \pm standard deviation: $30.49 \pm 21.30$ ); peak value during the hyperemic phase, 6.67 TPU (5.02 to 9.3); peak value-baseline difference, 3.62 TPU (1.88 to 4.58 ); reperfusion slope, $1.16 \mathrm{TPU} / \mathrm{second}$ (0.49 to 2.64 ) (normal values \pm standard deviation: $48.62 \pm 32.08$ ). There were no significant differences in these parameters between survivors and nonsurvivors (data not shown). The LD reperfusion slope tended to correlate with the $\mathrm{StO}_{2}$ reperfusion slope, but did not reach statistical significance $(P=0.08)$ (Figure $4 d$ ).

\section{Discussion}

This prospective, observational study follows the recently published study by Creteur and colleagues on severe sepsis and septic shock using the same device [22]. The primary new inputs of our study design are the selection of a very homogeneous population (that is, only septic shock patients having at least one additional organ failure), two techniques for microperfusion assessment $\left(\mathrm{StO}_{2}\right.$ and skin LD), a day 1 evaluation of the predictive value of the reperfusion slope with a clear difference in median between survivors and nonsurvivors, and an investigation of the potential determinants of the reperfusion slope (systemic hemodynamic and metabolic parameters such as lactate and the occlusion slope). Our $\mathrm{StO}_{2}$ parameters in septic shock confirm the observations made by Creteur and colleagues in septic shock: the muscle baseline $\mathrm{StO}_{2}$ is slightly lower in septic shock patients than in healthy controls; and only the $\mathrm{StO}_{2}$ reperfusion slope and not the occlusion slope is slower in septic shock than in healthy controls. In addition, the $\mathrm{StO}_{2}$ reperfusion slope was lower at day 1 in nonsurvivors than in survivors and predicted outcome within 28 days. The LD data, although abnormal, did not correlate well with $\mathrm{StO}_{2}$ parameters. The link between systemic hemodynamic or metabolic parameters with the $\mathrm{StO}_{2}$ reperfusion slope suggests an impact on tissue microoxygenation, even if their respective role cannot be precisely determined.

The development of non-invasive bedside tools to assess microperfusion alterations has prompted clinicians to look at the previously recognized and demonstrated microcirculation impairment occurring in severe sepsis or septic shock $[3,5,37]$. Among these tools, some image microvessel flowing conditions, such as sublingual orthogonal polarisation spectral (OPS) or sidestream dark field (SDF) $[5,38]$, some evaluate local tissue perfusion as carbon dioxide tonometry [39], some measure local tissue microvessel blood flow such as LD [35] and, finally, some assess tissue micro-oxygenation by NIRS [24].

NIRS uses the differential absorption properties of oxygenated and deoxygenated hemoglobin to evaluate oxygenation of tissues such as skeletal muscle. Near-infrared light (680 to $800 \mathrm{~nm}$ ) easily crosses biological tissues, which have a low absorption power, and is absorbed only by hemoglobin, myoglobin, and oxidized cytochrome, with the contribution of the latter two to the light attenuation signal being very small [30]. NIRS has several advantages since, in addition to being non-invasive, it is easy to use, does not require expertise to obtain adequate results, and is a continuous method providing numbers and continuous trends. NIRS has been used in different clinical conditions such as severe trauma [13-17], hemorrhagic shock $[40,41]$, cardiogenic shock or severe cardiac failure [42] and septic shock [18-22]. The limitations of NIRS should also be mentioned. Since this technique does not measure microvessel blood flow or capillary density, it has a signal ambiguity related to illumination of venous, capillary and arteriolar vessels. Several parameters can be obtained from NIRS numerical data, as demonstrated by De Blasi and colleagues [24]. Among these, the simplest parameters and the most understandable by the clinician are the baseline $\mathrm{StO}_{2}$ and the functional regional circulatory test (VOT) response [24]. The VOT was developed in septic shock because baseline $\mathrm{StO}_{2}$ did not clearly differ from controls [14-18], contrary to hemorrhagic trauma situations $[40,41]$. 
(a)

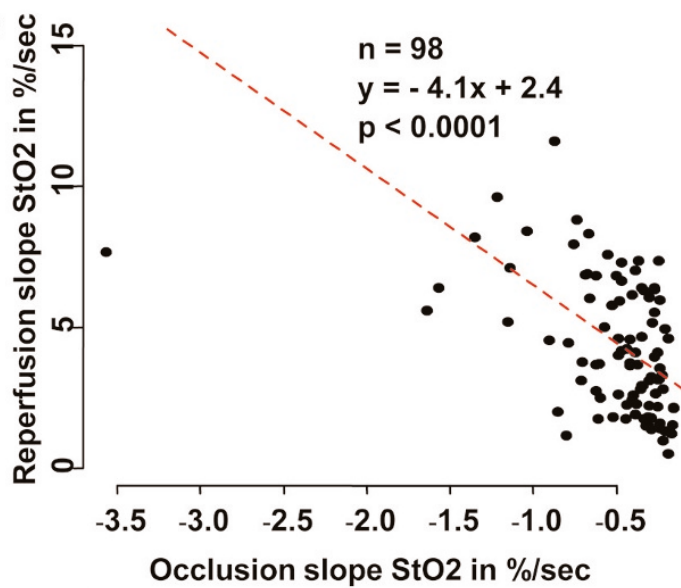

(c)

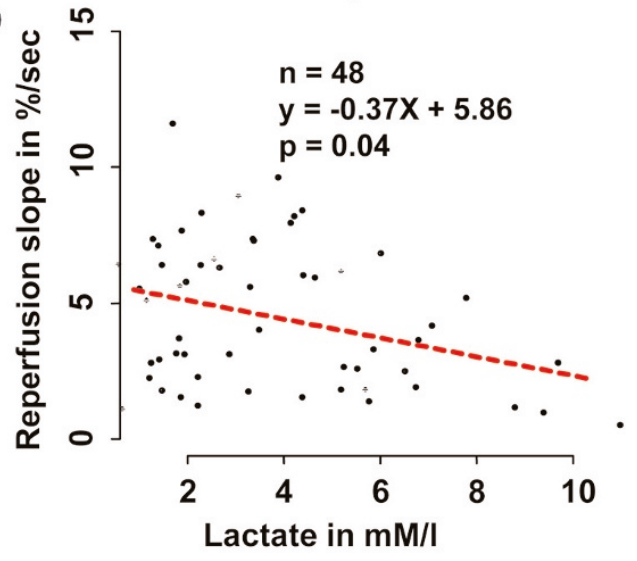

(b)

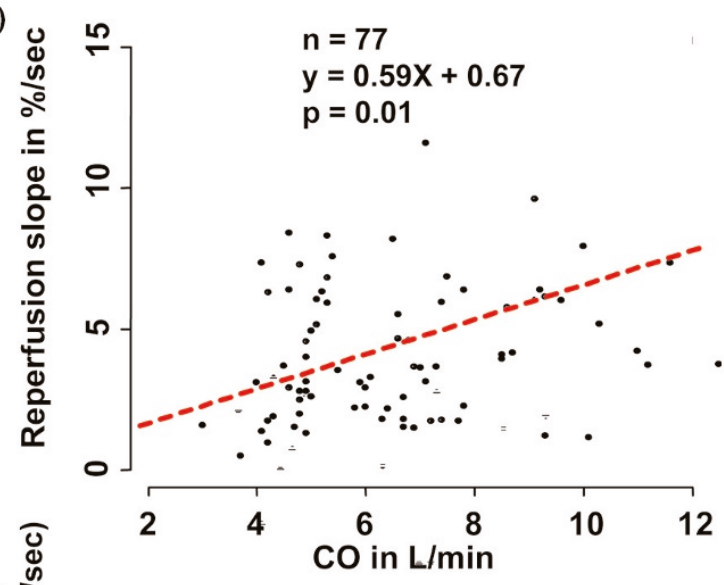

(d)

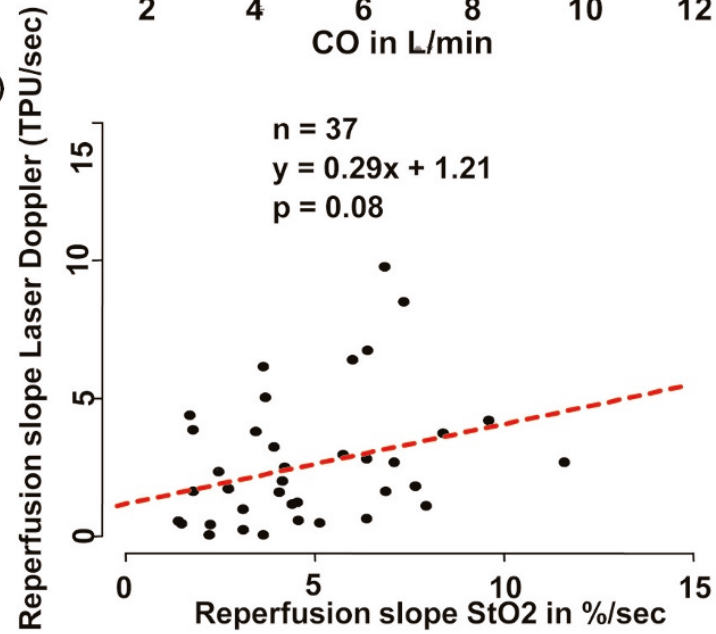

Correlation between hemodynamic and metabolic parameters and occlusion and reperfusion slopes. (a) Correlation between tissue hemoglobin oxygen saturation $\left(\mathrm{StO}_{2}\right)$ occlusion and reperfusion slopes for 98 measurements performed on 43 patients (day 1, 43 measurements; day 2, 34 measurements; day 3, 21 measurements) during the first 3 days of septic shock. (b) Correlation between reperfusion slope and cardiac output (CO) obtained for 77 measurements, corresponding to 33 patients on day 1, 28 patients on day 2, and 16 patients on day 3 . (c) Correlation between lactate plasma concentration and reperfusion slope (48 measurements), corresponding to 23 patients measured on day 1,18 patients on day 2, and seven patients on day 3. (d) Correlation between the reperfusion slope obtained with laser Doppler and the one obtained with $\mathrm{StO}_{2}$ during the simultaneous occlusion tests: 37 measurements were obtained, on 15 patients on day 1,13 patients on day 2, and nine patients on day 3. TPU, tissue perfusion units.

The initial studies on sepsis, severe sepsis or septic shock [14-17] have reported small differences in baseline $\mathrm{StO}_{2}$ compared with healthy controls. We confirm in the present study such a small, though significant, difference. Since the $\mathrm{StO}_{2}$ value at the thenar eminence is higher than the central $\mathrm{SvO}_{2}$ and lower than $\mathrm{SpO}_{2}$, we analyzed the potential meaning of the gradients between $\mathrm{StO}_{2}$ and these other oxygen saturations. Gradients did not differ between survivors and nonsurvivors, but, since their evolution was not studied, further investigation might be important to evaluate a potential impact on outcome or severity. We also found no correlation between $\mathrm{SpO}_{2}$ and $\mathrm{StO}_{2}$ or between $\mathrm{StO}_{2}$ and $\mathrm{SvO}_{2}$.

Whether $\mathrm{ScvO}_{2}$ is an adequate surrogate for $\mathrm{SvO}_{2}$ has been a matter of continuous debate. We pooled $\mathrm{ScvO}_{2}+5 \%$ and $\mathrm{SvO}_{2}$ values for the analysis. Both parameters are low in early septic shock and have been shown to be useful to detect and treat global tissue hypoxia during the resuscitation period. Although the absolute values of $\mathrm{ScvO}_{2}$ and $\mathrm{SvO}_{2}$ differ, studies have consistently shown close trends and tracking between the two in several hemodynamic conditions. The presence of a low $\mathrm{ScvO}_{2}$ indicates even lower $\mathrm{SvO}_{2}$, the difference being (on average) approximately $5 \%$. If joining both sources might have induced a small inaccuracy in the step-by-step numerical $\mathrm{StO}_{2}-\mathrm{SvO}_{2}$ gradient, therefore, this does not alter the fact that there was no correlation between them.

Many studies have also reported the time variations of $\mathrm{StO}_{2}$ slopes during the VOT, even when performed with different protocols - time to reach a low threshold of $40 \%[15,19]$ or a duration of 3 to 5 minutes of occlusion [18,20-22]. The 
Figure 5

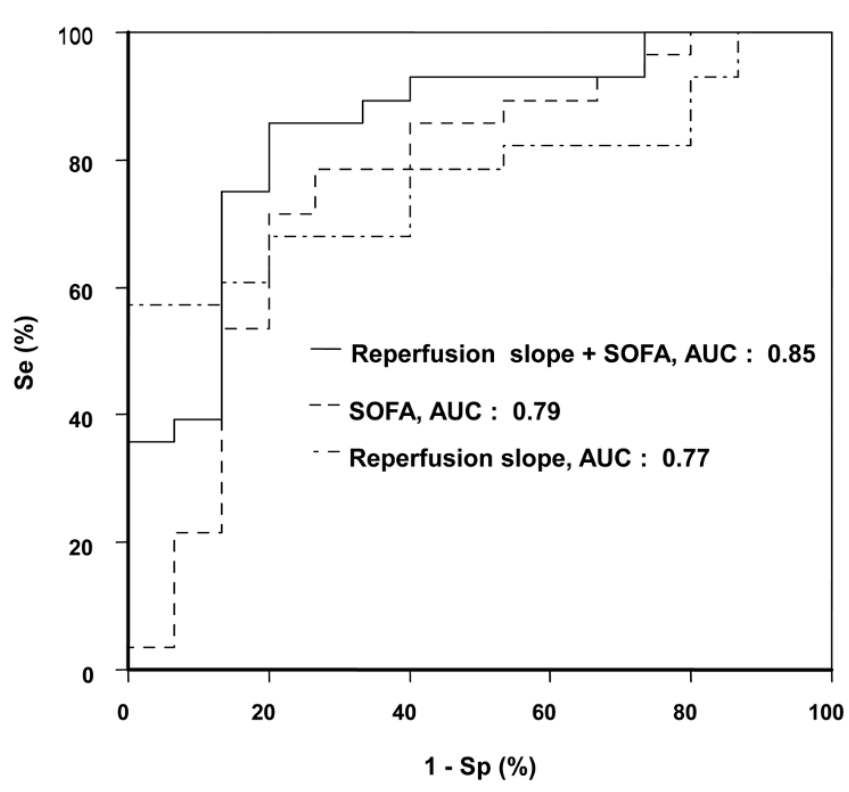

Predictive value on outcome. Area under the curve (AUC) for the multivariate model using each determinant alone or in combination (solid curve). Se, sensitivity; SOFA, Sequential Organ Failure Assessment; Sp, specificity.

present study confirms the previous results for baseline $\mathrm{StO}_{2}$ and for $\mathrm{StO}_{2}$ occlusion and reperfusion slopes [20-22]. Clearly, the $\mathrm{StO}_{2}$ reperfusion slope appears the most discriminating parameter for sepsis severity, as previously mentioned [22]. The reperfusion slope was slower in septic shock than in severe sepsis and was comparable with the values we obtained.

In addition, we observed for the first time that the $\mathrm{StO}_{2}$ reperfusion slope within the first 24 hours of septic shock was different between survivors and nonsurvivors at 28 days in this homogeneous population. Considering this difference, we decided to look at the predictive value for outcome of this parameter alone, in comparison or in combination with the SOFA score. Using multivariate analysis, we observed a good predictive value of the $\mathrm{StO}_{2}$ reperfusion slope, although not superior to the day 1 SOFA score. Unlike the SOFA score, however, the $\mathrm{StO}_{2}$ reperfusion slope can be obtained several times a day. Taking into account the number of $\mathrm{StO}_{2}$ values measured during the reperfusion time (one value every 3 seconds), only five or six values can be obtained. This small number of values may induce error in the slope calculation, especially if the tracing is not linear. Consequently, we decided to apply the linear adjustment model and check the $R^{2}$ value. It was only when $R^{2}$ was $>0.90$ that we took the linear slope value. Nonlinear reperfusion tracings were observed in $20 \%$ of the performed VOTs. The recent development of the incorporated software in the device has integrated this calculation online.
Although performed on both severe sepsis patients and septic shock patients, the reported area under the receiver operating characteristic curve for the $\mathrm{StO}_{2}$ reperfusion slope outcome predictive value [22] was comparable with the one we obtained in septic shock patients (0.797 vs. 0.77, respectively), suggesting a good reproducibility. The calculated threshold for the reperfusion slope (2.83\%/second) was also very similar to the one previously reported (2.55\%/second) [22], with a sensitivity of $80 \%$ and a specificity of $67 \%$. This area under the curve was also similar to that obtained with day 1 SOFA values (0.79). Combining the $\mathrm{StO}_{2}$ reperfusion slope and SOFA score predictive values showed a significant amelioration of predictive value, raising the area under the curve to 0.85 .

As the most discriminating parameter for outcome and severity [22], the determinants of the $\mathrm{StO}_{2}$ reperfusion slope require discussion. The relationship with macrohemodynamics is the first line of investigation. We observed a significant relation only between cardiac output and the $\mathrm{StO}_{2}$ reperfusion slope, which has never been reported before in septic shock - such a relation had only been shown in severe cardiac failure [42]. Although weak $(P<0.01)$, the relation indicates that systemic flow influences thenar $\mathrm{StO}_{2}$. Classically in septic shock, adequacy of perfusion for oxygen demand is assessed by the blood lactate level. In the present study, the lactate level logically negatively correlated with the $\mathrm{StO}_{2}$ reperfusion slope, which was slower when lactate levels were higher. This suggests that NIRS can detect poor tissue oxygenation or bad vascular reserve that results in lactate elevation during septic shock. Taking these relationships (cardiac output and lactate) into account, it is reasonable to think that poor perfusion at the systemic level influences an abnormal $\mathrm{StO}_{2}$ reperfusion slope. Separating the hyperproduction of lactate from a stagnant elevation of lactate level is not possible due to poor washout.

The second line of determinants may relate to local perfusion, which may be impaired because of low microvessel blood flow or the low density of perfused microvessels. In addition, changes in vascular blood compartmentalization between venules, capillaries and small arteries may also influence the $\mathrm{StO}_{2}$ measurement. Despite limitations, initial investigation of these determinants was made measuring forearm skin blood flow using LD at baseline and during the same VOT performed for $\mathrm{StO}_{2}$. In this population of septic shock patients, the LD baseline and the VOT response were abnormal in comparison with healthy volunteers. The abnormal hyperemic response has been attributed to an abnormal capability of the vessels to dilate after ischemia, mediated by a deficit in vasodilatating substances such as prostaglandins or nitric oxide $[2,6,9,43]$. The nearly significant $(P=0.08)$ correlation between LD and the $\mathrm{StO}_{2}$ reperfusion slopes is important, since the relation between skin LD and $\mathrm{StO}_{2}$ parameters has not been reported previously. The slower the $\mathrm{StO}_{2}$ slope, the slower the reperfusion slope of 
the LD. The combination of a small number of patients and the differences between skin blood flow and skeletal muscle flow regulations may explain the weakness of the correlation [33]. This suggests a potential impact of microvessel blood flow in the observed abnormal $\mathrm{StO}_{2}$ reperfusion slope.

The observed strong correlation between $\mathrm{StO}_{2}$ occlusion and reperfusion slopes needs further discussion; that is, the deeper the occlusion slope, the faster the reperfusion slope. The explanation for such an observation can only be speculated on the basis of the previous demonstration of the determinants of these slopes [15,19-22,24]. The $\mathrm{StO}_{2}$ occlusion slope seems to relate primarily to muscle oxygen consumption. It was shown that the higher the muscle oxygen consumption, the faster will be the $\mathrm{StO}_{2}$ decay over time [18$21,24]$. In our septic shock population, the correlation may depend on the importance of muscle ischemia created by the VOT. Occurring faster after occlusion, the ischemia will be longer - which might induce a more pronounced muscle ischemia, with the release of more vasodilating substances. This aspect requires further investigation for clarification.

\section{Conclusion}

In the present study, the $\mathrm{StO}_{2}$ reperfusion slope is an early predictive value for outcome in septic shock patients. Its performance improves when combined with well-known severity scores. Some relations between macroperfusion and microperfusion influence the measured $\mathrm{StO}_{2}$ variables. When $\mathrm{StO}_{2}$ baseline values indicate adequate perfusion, but microcirculatory dysfunction is suspected, the use of the VOT seems promising for a functional microperfusion evaluation. Because of the intricate determinants of microperfusion, a multimodal assessment to better characterize microperfusion is needed. Further studies are warranted to validate the NIRS measurements using a different probe $(15 \mathrm{~mm})$ working more superficially in the thenar eminence than the probe used initially $(25 \mathrm{~mm})$.

\section{Competing interests}

The authors declare that they have no competing interests.

\section{Acknowledgements}

The present work was supported in part by a grant from University Paris 7 Denis Diderot, Plan Quadriennal 2004-2008, and by an unrestricted fund for research from Hutchinson Technologies. CL received a grant for performing research on microcirculation from Hutchinson Technologies.

This article is part of Critical Care Volume 13 Supplement 5: Tissue oxygenation $\left(\mathrm{StO}_{2}\right)$ in healthy volunteers and critically-ill patients. The full contents of the supplement are available online at http://ccforum. $\mathrm{com} /$ supplements/13/S5. Publication of the supplement has been supported with funding from Hutchinson Technology Inc.

\section{References}

1. Levy MM, Fink MP, Marshall JC, Abraham E, Angus D, Cook D, Cohen J, Opal SM, Vincent JL, Ramsay G: 2001 SCCM/ESICM/ ACCP/ATS/SIS International Sepsis Definitions Conference. Crit Care Med 2003, 31:1250-1256.

2. Ince C, Sinaasappel M: Microcirculatory oxygenation and shunting in sepsis and shock. Crit Care Med 1999, 27:1369-1377.
3. Spronk PE, Zandstra DF, Ince C: Bench-to-bedside review: sepsis is a disease of the microcirculation. Crit Care 2004, 8: 462-468.

4. Kirschenbaum LA, Aziz M, Astiz ME, Saha DC, Rackow EC: Influence of rheologic changes and platelet-neutrophil interactions on cell filtration in sepsis. Am J Respir Crit Care Med 2000, 161:1602-1607.

5. De Backer D, Creteur J, Preiser JC, Dubois MJ, Vincent JL: Microvascular blood flow is altered in patients with sepsis. Am J Respir Crit Care Med 2002, 166:98-104.

6. Ince C: The microcirculation is the motor of sepsis. Crit Care 2005, 9(Suppl 4):S13-S19.

7. Rivers EP: Early goal-directed therapy in severe sepsis and septic shock: converting science to reality. Chest 2006, 129: 217-218.

8. Sakr Y, Dubois MJ, De Backer D, Creteur J, Vincent JL: Persistent microcirculatory alterations are associated with organ failure and death in patients with septic shock. Crit Care Med 2004, 32:1825-1831.

9. Spronk PE, Ince C, Gardien MJ, Mathura KR, Oudemans-van Straaten HM, Zandstra DF: Nitroglycerin in septic shock after intravascular volume resuscitation. Lancet 2002, 360:13951396.

10. Pastor CM, Losser MR, Payen D: Nitric oxide donor prevents hepatic and systemic perfusion decrease induced by endotoxin in anesthetized rabbits. Hepatology 1995, 22:1547-1553.

11. De Backer D, Verdant C, Chierego M, Koch M, Gullo A, Vincent JL: Effects of drotrecogin alfa activated on microcirculatory alterations in patients with severe sepsis. Crit Care Med 2006, 34:1918-1924.

12. Kirschenbaum LA, Lopez WC, Ohrum P, Tsen A, Khazin J, Astiz ME: Effect of recombinant activated protein $C$ and low-dose heparin on neutrophil-endothelial cell interactions in septic shock. Crit Care Med 2006, 34:2207-2212.

13. Ward KR, Ivatury RR, Barbee RW, Terner J, Pittman R, Filho IP, Spiess B: Near infrared spectroscopy for evaluation of the trauma patient: a technology review. Resuscitation 2006, 68: 27-44.

14. Crookes BA, Cohn SM, Burton EA, Nelson J, Proctor KG: Noninvasive muscle oxygenation to guide fluid resuscitation after traumatic shock. Surgery 2004, 135:662-670.

15. Gomez H, Torres A, Polanco P, Kim HK, Zenker S, Puyana JC, Pinsky MR: Use of non-invasive NIRS during a vascular occlusion test to assess dynamic tissue $\mathrm{O}_{2}$ saturation response. Intensive Care Med 2008, 34:1600-1607.

16. Moore FA, Nelson T, McKinley BA, Moore EE, Nathens AB, Rhee P, Puyana JC, Beilman GJ, Cohn SM: Massive transfusion in trauma patients: tissue hemoglobin oxygen saturation predicts poor outcome. J Trauma 2008, 64:1010-1023.

17. Cohn SM, Nathens AB, Moore FA, Rhee P, Puyana JC, Moore EE, Beilman GJ: Tissue oxygen saturation predicts the development of organ dysfunction during traumatic shock resuscitation. J Trauma 2007, 62:44-54; discussion 54-45.

18. De Blasi RA, Palmisani S, Alampi D, Mercieri M, Romano R, Collini S, Pinto G: Microvascular dysfunction and skeletal muscle oxygenation assessed by phase-modulation near-infrared spectroscopy in patients with septic shock. Intensive Care Med 2005, 31:1661-1668.

19. Pareznik R, Knezevic R, Voga G, Podbregar M: Changes in muscle tissue oxygenation during stagnant ischemia in septic patients. Intensive Care Med 2006, 32:87-92.

20. Doerschug KC, Delsing AS, Schmidt GA, Haynes WG: Impairments in microvascular reactivity are related to organ failure in human sepsis. Am J Physiol Heart Circ Physiol 2007, 293: $\mathrm{H} 1065-\mathrm{H} 1071$.

21. Skarda DE, Mulier KE, Myers DE, Taylor JH, Beilman GJ: Dynamic near-infrared spectroscopy measurements in patients with severe sepsis. Shock 2007, 27:348-353.

22. Creteur J, Carollo T, Soldati G, Buchele G, De Backer D, Vincent JL: The prognostic value of muscle $\mathrm{StO}_{2}$ in septic patients. Intensive Care Med 2007, 33:1549-1556.

23. Uilkema RJ, Groeneveld AB: Correlates of thenar near-infrared spectroscopy-derived tissue $\mathrm{O}_{2}$ saturation after cardiac surgery. Interact Cardiovasc Thorac Surg 2007, 6:265-269.

24. De Blasi RA, Ferrari M, Natali A, Conti G, Mega A, Gasparetto A: Noninvasive measurement of forearm blood flow and oxygen consumption by near-infrared spectroscopy. J Appl Physiol 
1994, 76:1388-1393

25. Valtier B, Cholley BP, Belot JP, de la Coussaye JE, Mateo J, Payen DM: Noninvasive monitoring of cardiac output in critically ill patients using transesophageal Doppler. Am J Respir Crit Care Med 1998, 158:77-83.

26. Dellinger RP, Carlet JM, Masur $\mathrm{H}$, Gerlach $\mathrm{H}$, Calandra $\mathrm{T}$, Cohen J, Gea-Banacloche J, Keh D, Marshall JC, Parker MM, Ramsay G, Zimmerman JL, Vincent JL, Levy MM; Surviving Sepsis Campaign Management Guidelines Committee: Surviving Sepsis Campaign guidelines for management of severe sepsis and septic shock. Crit Care Med 2004, 32:858-873.

27. Le Gall JR, Lemeshow S, Saulnier F: A new Simplified Acute Physiology Score (SAPS II) based on a European/North American multicenter study. JAMA 1993, 270:2957-2963.

28. Vincent JL, Moreno R, Takala J, Willatts S, De Mendonca A, Bruining $H$, Reinhart CK, Suter PM, Thijs LG: The SOFA (Sepsisrelated Organ Failure Assessment) score to describe organ dysfunction/failure. On behalf of the Working Group on Sepsis-Related Problems of the European Society of Intensive Care Medicine. Intensive Care Med 1996, 22:707-710.

29. Rivers E: Mixed vs central venous oxygen saturation may be not numerically equal, but both are still clinically useful. Chest 2006, 129:507-508.

30. Myers DE, Anderson LD, Seifert RP, Ortner JP, Cooper CE, Beilman GJ, Mowlem JD: Noninvasive method for measuring local hemoglobin oxygen saturation in tissue using wide gap second derivative near-infrared spectroscopy. J Biomed Opt 2005, 10:034017.

31. Baron JF, Payen D, Coriat P, Edouard A, Viars P: Forearm vascular tone and reactivity during lumbar epidural anesthesia. Anesth Analg 1988, 67:1065-1070.

32. Payen D, Ecoffey C, Carli P, Dubousset AM: Pulsed Doppler ascending aortic, carotid, brachial, and femoral artery blood flows during caudal anesthesia in infants. Anesthesiology 1987, 67:681-685.

33. Vissing SF: Differential activation of sympathetic discharge to skin and skeletal muscle in humans. Acta Physiol Scand Suppl 1997, 639:1-32.

34. Poeze M: Tissue-oxygenation assessment using near-infrared spectroscopy during severe sepsis: confounding effects of tissue edema on $\mathrm{StO}_{2}$ values. Intensive Care Med 2006, 32: 788-789.

35. Neviere R, Mathieu D, Chagnon JL, Lebleu N, Millien JP, Wattel F: Skeletal muscle microvascular blood flow and oxygen transport in patients with severe sepsis. Am J Respir Crit Care Med 1996, 153:191-195.

36. R: A Language and Environment for Statistical Computing [http://www.R-project.org]

37. Sair M, Etherington PJ, Peter Winlove C, Evans TW: Tissue oxygenation and perfusion in patients with systemic sepsis. Crit Care Med 2001, 29:1343-1349.

38. Groner W, Winkelman JW, Harris AG, Ince C, Bouma GJ, Messmer K, Nadeau RG: Orthogonal polarization spectral imaging: a new method for study of the microcirculation. Nat Med 1999, 5:1209-1212.

39. Weil $\mathrm{MH}$ : Tissue $\mathrm{PCO}_{2}$ as universal marker of tissue hypoxia. Minerva Anestesiol 2000, 66:343-347.

40. Beilman GJ, Groehler KE, Lazaron V, Ortner JP: Near-infrared spectroscopy measurement of regional tissue oxyhemoglobin saturation during hemorrhagic shock. Shock 1999, 12:196200.

41. Taylor JH, Mulier KE, Myers DE, Beilman GJ: Use of nearinfrared spectroscopy in early determination of irreversible hemorrhagic shock. J Trauma 2005, 58:1119-1125.

42. Podbregar $M$, Mozina $H$ : Skeletal muscle oxygen saturation does not estimate mixed venous oxygen saturation in patients with severe left heart failure and additional severe sepsis or septic shock. Crit Care 2007, 11:R6.

43. Losser MR, Forget AP, Payen D: Nitric oxide involvement in the hemodynamic response to fluid resuscitation in endotoxic shock in rats. Crit Care Med 2006, 34:2426-2431. 